\title{
É POSSÍVEL UMA REFORMULAÇÃO DO IMORALISMO COGNITIVO DE KIERAN?
}

\author{
A REFORMULATION OF KIERAN COGNITIVE IMMORALISM IS POSSIBLE?
}

Gustavo Luiz Pozza*

\section{RESUMO}

Dada a tendência de que se avalie moralmente a experiência estética, a filosofia contemporânea tem desenvolvido linhas de avaliação ético-estéticas que propõem soluções divergentes para o equilíbrio desses valores. Matthew Kieran propõe uma corrente que defende o imoralismo como uma associação entre falhas morais e méritos estéticos, bem como um imoralismo cognitivo, no qual o espectador, pela vivência da imoralidade no universo ficcional da obra, pode questionar seus valores morais. Entretanto, a proposta de Kieran não nega o eticismo, passo necessário para que se suprima um relativismo moral derivado da moralização, e acaba por retornar ao problema da bifurcação forma-conteúdo do esteticismo. Diante desses problemas resultantes dessa formulação do imoralismo, propõe-se uma nova formulação do imoralismo cognitivo que negue o moralismo sem resultar na proposta amoral do esteticismo e que, ainda, afirme o cognitivismo. O resultado é uma possibilidade de modificação na proposta de Kieran que acrescente a ciência da imoralidade pelo espectador, uma vez que o conflito entre seus valores morais e os apresentados pela obra são imprescindíveis para a aplicação da teoria.

PALAVRAS-CHAVE: Imoralismo. Estética. Ética. Cognitivismo. Arte.

\section{ABSTRACT}

Given the tendency to morally evaluate the aesthetic experience, contemporary philosophy has developed ethical-aesthetic lines of evaluation that propose divergent solutions to the balance of these values. Matthew Kieran proposes a theory that defends immoralism as an association between moral failures and aesthetic merits, as well as a cognitive immoralism, in which the viewer, through the experience of immorality in the fictional universe of the work, can question his moral values. However, Kieran's proposal does not negate ethicalism, a necessary step in suppressing moral relativism derived from moralization, and eventually returns to the problem of the form-content bifurcation of aestheticism. Given these problems resulting from this formulation of immoralism, it is proposed a new formulation of cognitive immoralism wich denies moralism without resulting in the amoral proposal of aestheticism and that affirms cognitivism. The result is a possibility of modification in Kieran's proposal that adds the spectator's science of immorality, since the conflict between his moral values and those presented by the work are indispensable for the application of the theory.

KEYWORDS: Immoralism. Aesthetics. Ethics. Cognitivism. Art.

\footnotetext{
* Mestre em Filosofia pela UCS. Graduação em fotografia e especialização em Imagem Publicitária pela PUCRS. TemE-mail: glpozza@gmail.com.
}

Sapere aude - Belo Horizonte, v. 10 - n. 20, p. 750-764, Jul./Dez. 2019 - ISSN: 2177-6342 


\section{INTRODUÇÃO}

Dada a tendência de que se avalie moralmente a experiência estética, a filosofia contemporânea tem desenvolvido linhas de avaliação ético-estéticas que propõem soluções divergentes para o equilíbrio desses valores. Tendo o moralismo - a defesa de que falhas morais sejam equivalentes a falhas estéticas - comprovado a capacidade cognitiva da arte, ou seja, de que o espectador possa aprender moralmente pela narrativa das obras, mas não garantido a afirmação de uma simetria entre discurso moral e moralização do espectador, Matthew Kieran propõe uma corrente que defende o imoralismo como uma associação entre falhas morais e méritos estéticos, bem como de um imoralismo cognitivo, no qual o espectador, pela vivência da imoralidade no universo ficcional da obra, possa questionar seus valores morais, reforçando-os, numa proposta filosófica da noção de senso comum em que para que se conheça o bom é preciso experienciar o mau. Entretanto, a proposta de Kieran de aprender pelo mau como justificativa para aceitar a imoralidade no cognitivismo estético não nega o eticismo, passo necessário para que se suprima um relativismo moral na avaliação da arte que é derivado dessa corrente, e retorna ao problema da bifurcação forma-conteúdo do esteticismo. Diante desses problemas resultantes dessa formulação, é preciso que se questione se é possível outra formulação do imoralismo cognitivo que, simultaneamente, negue o moralismo, desvie do amoralismo e da bifurcação do eticismo e afirme o cognitivismo.

Nesse sentido, o presente artigo propõe um levantamento do estado da arte da discussão ético-estética, uma apresentação do cognitivismo estético e da proposta do Imoralismo cognitivo como formulada por Kieran para, subsequentemente, defender uma revisão da proposição fonte da objeção.

\section{ESTETICISMO}

As duas questões principais que compõem o estudo da moralidade na arte dizem respeito à capacidade da obra de arte de corromper o espectador e se, uma vez que a obra tenha tal capacidade, é possível propor a omissão ou controle dessas obras imorais. Dada a constância com que tais questionamentos ocorrem, surgem na filosofia contemporânea três correntes principais de avaliação da relação entre ética e estética: o esteticismo, o contextualismo e o moralismo. As três correntes partem de uma tentativa de justificação da equivalência entre os valores estéticos e os valores éticos, ou seja, se as falhas éticas da obra 
de arte devam obrigatoriamente ser vistas como falhas estéticas, ou mesmo se existe uma relação entre esses elementos avaliativos.

Para a corrente esteticista ou autonomista, exposta mas não defendida por Gaut (2007, p. 10), os problemas éticos apresentados em uma obra não devem nunca ser tratados como problemas estéticos. Essa corrente defende a arte pela arte, a visão de que a arte deva ser produzida e consumida apenas por seu valor estético, em vez de outras capacidades como o aperfeiçoamento moral. A dificuldade de defesa dessa corrente está na impossibilidade de avaliação de alguns elementos estéticos destacados de seu valor moral, como se procura demonstrar a seguir.

Esse movimento de avaliação moral da arte parte de uma falsa dicotomia entre moralismo e formalismo, o que Jacobson (1997, p. 157) chama de bifurcação, ao tentar tratar a obra como constituída por elementos estéticos e pelo conteúdo que transmite ao espectador, como se esses dois componentes fossem heterogêneos e desassociáveis. Essa divisão não parece levar em conta a impossibilidade de que se apresente um conteúdo ao espectador sem que esse conteúdo seja representado pelos elementos formais, bem como a de que não se podem considerar os elementos formais unicamente, sem que se avalie a mensagem que transmitem.

Por mais que possam existir manifestações artísticas puramente formais, pontualmente a música instrumental e a pintura abstrata, ao se considerar a arte como uma manifestação que resulta do período em que se apresenta e, por isso, imbuída de transmitir uma narrativa que reflete uma opinião moral sobre o estado da realidade, é necessário que se veja a relação forma-conteúdo como indivisível para a transmissão da mensagem da arte.

Utilize-se como exemplo o filme $O$ triunfo da vontade de Leni Riefenstahl, obra constantemente associada às discussões sobre ética na arte devido a sua importância estética e valor técnico no desenvolvimento da linguagem cinematográfica, associados a um discurso de exaltação do nazismo. A avaliação autonomista sugere que se deva perceber apenas o formalismo constitutivo da obra separado de seus elementos narrativos. Visto que é preciso considerar a mensagem que está sendo transmitida - a defesa do nacional-socialismo, nesse caso - para que se possa considerar a efetividade com que essa transmissão acontece, bem como as escolhas estéticas da diretora em apresentar seus elementos narrativos; é a relação entre esses dois elementos que dá valor a obra, não sendo portanto possível separá-los. Ainda assim, uma defesa dessa corrente poderia insistir na validade estética de obras com problemas 
éticos e no prejuízo resultante de sua omissão. A dissociação obrigatória entre ética e estética possibilitaria, certamente, uma percepção e validação de obras de arte apesar de suas posições éticas. O mesmo exemplo de $O$ triunfo da vontade serve para lembrar que, embora se tenha ciência de seu discurso, a obra de Riefenstahl continua sendo uma referência estética cinematográfica e, de forma alguma, poderia ser desconsiderada e eliminada da história do cinema.

Uma tentativa de validação dessa proposta está no que Gaut (2007, p. 76) chama de autonomismo moderado, em que é preciso avaliar moralmente a obra, mas sem que essa avaliação prejudique a avaliação estética. Assim, é permitido que se tenha conhecimento dos problemas éticos, desde que sejam considerados um problema em si e não como parte do todo, e se avalie a maneira como esses problemas são expressos pela obra. Nessa corrente, a obra de Riefenstahl seria percebida como portadora de uma série de problemas éticos, mas a avaliação estética deveria apenas considerar como esse discurso é apresentado cinematograficamente, não se essa mensagem deve ser avaliada como parte da obra. $\mathrm{O}$ problema que resulta dessa afirmação, nesse caso, é como avaliar um discurso pela maneira que ele se apresenta, quando seu conteúdo e a efetividade da compreensão pelo espectador são indispensáveis para a percepção dos elementos formativos do discurso.

O autonomismo demostra, assim, que é na própria existência de casos particulares de avaliação, como a obra cinematográfica citada, que fica comprovada sua inaplicabilidade, uma vez que tais casos que deveriam justificar essa corrente acabam por negá-la. Assim, considerando-se que a proposta é validar esteticamente a mensagem e que, para isso, seria necessário desconsiderar a mensagem, o autonomismo se prova inadequado como proposta de avaliação estética.

\section{MORALISMO}

O moralismo, para Kieran (2006, p. 56), é a proposta de que as avaliações moral e estética sejam diretamente relacionadas na arte. Na sua versão extrema, o moralismo defende que o valor artístico é, fundamentalmente, valor moral e, mesmo em suas versões mais moderadas e contemporâneas, impede a associação de valor estético a uma obra que seja tida como imoral. Uma versão moderada, chamada de eticismo, defende que as falhas éticas devam ser consideradas dada sua relevância estética. Essa é a visão usualmente associada ao 
conservadorismo nas artes e, principalmente, utilizada como justificativa para a censura de obras a partir de sua temática ${ }^{1}$.

Jacobson critica essa visão que considera que uma obra é imoral e, portanto, prejudicial, simplesmente por retratar um comportamento imoral: "Aqueles que acusam a cultura popular de glorificar o vício podem estar afirmando que a audiência [...] não responde à narrativa como uma narrativa, mas em uma maneira como 'macaco vê, macaco faz'." (JACOBSON, 1997, p. 164, tradução nossa) ${ }^{2}$.

Provém daí a ideia de que obras de arte devam demonstrar a punição do vício e a recompensa da virtude. Essa visão do espectador como alguém que absorve a mensagem da obra e que a repete sem que haja uma racionalidade envolvida na compreensão, além de subestimar a capacidade do público, suporta o conceito de uma moralização obrigatória da narrativa. Entretanto, a proposta eticista, ao defender a moralização da arte pelo efeito cognitivo no espectador, acaba por validar a afirmação de que é possível transmitir conhecimento através da obra de arte.

\subsection{COGNITIVISMO ESTÉTICO}

Nesse contexto pode-se afirmar que, uma vez que uma obra de arte é capaz de transmitir conhecimento, e que isso é, em algumas condições, um mérito estético da obra, se uma obra é capaz de transmitir uma forma específica de conhecimento, como um valor moral, essa transmissão de conhecimento moral é uma capacidade estética da obra - o que é conhecido como cognitivismo estético (GAUT, 2007, p. 136).

Uma ressalva deve ser feita quanto à capacidade cognitiva: a obra de arte pode transmitir conhecimento sem necessariamente ser isso uma qualidade estética. Pinturas ou fotografias antigas podem carregar informações sobre um determinado povo ou época, sem que isso seja um mérito estético da obra. É preciso considerar ainda que nem todo conhecimento transmitido de uma fonte depende de que essa fonte possua entendimento do que está afirmando. Visto que é possível aprender pelo erro dos outros, não é necessário que a

\footnotetext{
${ }^{1}$ Embora Gaut (2007, p. 12) afirme que não há uma conexão direta entre o moralismo e a censura, uma vez que "possuir um defeito estético não é base para a censura da arte", obras de arte são notadamente censuradas em função de não corresponderem a um critério artístico que ultrapasse ou justifique suas falhas morais.

${ }^{2}$ Those who accuse popular culture of glorifying vice may be claiming that the audience - or at least its most callow and impressionable members - does not in fact respond to narrative art as narrative, but in something more like a "monkey-see, monkey-do" fashion.
} 
intenção do agente seja a de transmitir conhecimento para que isso ocorra. A estranha noção da realidade de alguém que defenda uma teoria da conspiração, por exemplo, não ensina sobre a possibilidade de realidades alternativas, mas sobre a "capacidade dos humanos de criarem elaboradas fantasias cognitivas" (GAUT, 2007, p. 186, tradução nossa) ${ }^{3}$.

A afirmação estética, essa resposta empática ao conflito moral na obra, resultado da compreensão da arte como capaz de transmitir valores morais, pode ser dividida em três etapas necessárias para a transmissão efetiva do conhecimento da obra para o espectador: entendimento, comunicação e ganho cognitivo. Essas três etapas - que correspondem, respectivamente, à capacidade do espectador de decodificar a obra e de ter ciência da problemática moral, ou mesmo da obra em se fazer compreensível ao utilizar elementos lógicos e compreensíveis no contexto de apresentação; ao mérito estético da obra em transmitir sua mensagem narrativa de forma eficiente; e, por fim, ao aprofundamento do conhecimento do espectador, pois seu conhecimento e posições prévias são colocados à prova pelo que apresenta a narrativa da obra - levam a uma reafirmação das capacidades estéticocomunicacionais da obra como parte de uma estrutura narrativa com vistas à construção de uma realidade interna de apreciação da obra.

O cognitivismo estético considera que o conhecimento moral depende, ao menos em algumas situações, de um mérito estético da obra, ou seja, de um aspecto comunicacional da arte, que permita ao espectador não só ser informado da premissa moral e de conhecer afirmações, mas de responder empaticamente a esse valor, de ter uma resposta condizente com o conflito moral apresentado.

Essa proposta de uma interação correta do espectador, chamada de resposta meritória por Gaut (2007, p. 228), espera que a obra provoque no espectador uma resposta adequada ao problema ético, uma vez que o comportamento moral do espectador o impediria de sentir alguma conexão com uma narrativa imoral, sendo que a avaliação moral da obra depende dessa capacidade de provocar a resposta esperada e moralmente adequada. Essa afirmação leva a entender ainda que as obras de arte devam, obrigatoriamente, possuir uma única interpretação correta e, por mérito estético, exigir o envolvimento correto do espectador.

Jacobson (1997, p. 172) busca refutar o argumento da resposta adequada de Gaut

\footnotetext{
${ }^{3}$ I may learn from a Flat-Earther, who accosts me on my doorstep with his crazy views; but what I learn is not what he is trying to teach me, that the earth is flat, but, rather, something about the ability of humans to produce elaborate cognitive fantasies.
} 
utilizando como exemplo a comédia. Considerar que uma piada ofensiva não é uma boa piada, uma vez que é imoral, é diferente de considerar que não seja engraçada. Além disso, é possível que seja o próprio elemento imoral que dê valor cômico para a narrativa. Sendo a primeira afirmação do argumento da resposta meritória que a arte imoral evoque sentimentos e respostas que são inadequados e antiéticos, Jacobson procura demonstrar que a resposta adequada que provém do humor não depende de sua moralidade, mas de sua capacidade de ser risível, ou seja, "o julgamento de que uma emoção é inadequada aos sentidos [...] é logicamente distinta do julgamento de que a reposta seja injustificada" (JACOBSON, 1997, p. 173, tradução nossa) ${ }^{4}$.

Que se possa aprender moralmente a partir da obra de arte que represente a imoralidade é uma afirmação que não pode ser feita sem que se levantem algumas objeções. Carroll (2003, p. 299) assume uma posição cética quanto à forma como o conhecimento pode ser transmitido a partir da arte, para que possa encontrar sustentações para a defesa dessa teoria. A principal tentativa de refutação da educação moral pela arte vem da necessidade de que se saiba a priori da imoralidade de determinada ação apresentada para que se compreenda sua importância na narrativa. Carrol defende que o processo de educação moral se dá a partir da ideia de que o espectador já tem conhecimento prévio sobre as proposições morais, o que o leva a entender o dilema moral apresentado, mas que é para além desse conhecimento que a obra de arte educará.

Essa resposta ao problema do conhecimento prévio diz respeito à profundidade da compreensão do espectador (GAUT, 2007, p. 139), ou seja, que o conhecimento moral não depende apenas do conhecimento das proposições morais, mas da resposta a elas e do envolvimento do espectador a sua presença na obra, uma vez que o exercício e a compreensão de como as emoções e os reflexos do espectador se dão frente à imoralidade são tão educativos quanto a percepção de tal imoralidade. Paralelo a isso, a arte é também uma oportunidade de que se percebam as nuances - por vezes muito sutis - da lógica e do ponto de vista de um personagem com pontos de vista pouco familiares.

Saber da imoralidade do assassinato, por exemplo, é condição necessária para a compreensão da trama de Crime e castigo, mas não é suficiente para que seu desenvolvimento na trama e seu efeito em Raskólnikov sejam compreendidos. Assim, o conhecimento do

\footnotetext{
${ }^{4}$ The judgment that an emotion is wrong to feel, or that it would be bad for you to feel it, is logically distinct from the judgment that the response is unwarranted.
} 
espectador sobre a imoralidade do assassinato e seu efeito no personagem de Dostoievski, embora já existisse anteriormente, pode ser aprofundado por sua reação a essa vivência na obra. Segue daí que a reação esperada foi resultado de uma capacidade da obra de, a partir do conhecimento prévio do espectador, envolvê-lo emocionalmente na narrativa e provocar uma resposta. Diferente de gerar no espectador um envolvimento correto, a obra de arte o faz questionar sua moralidade pessoal e sua resposta frente ao dilema, o que é, em si, um mérito estético.

Liberado de seus extremismos, como a afirmação do cognitivismo estético apenas a partir de algumas seletas obras capazes de provocar uma deliberação moral, o eticismo de Gaut se aproxima cada vez mais do contextualismo, como será apresentado a seguir. Embora o autor se esforce em uma defesa lógica de uma avaliação ético-estética única, seus exemplos comprovam a possibilidade de que se possa educar através da arte, mas não de que a arte precise ser um exemplo moral para que essa educação aconteça. Se a validade estética está na maneira como a arte se vale dos conhecimentos do espectador para ensinar, é permitido à arte que apresente elementos imorais para levantar questionamentos morais.

Assim, levando-se em consideração que não é proposta da arte fazer unicamente simples afirmações de valores morais, mas de oportunizar uma experiência de moralidade a partir de sua realidade narrativa, e que o espectador deva ter uma resposta adequada moralmente ao dilema moral apresentado, resposta essa fundamentada nos seus valores morais apriorísticos, a afirmação do cognitivismo estético não pressupõe que os valores apresentados pela obra sejam obrigatoriamente morais, mas sim que oportunizem uma experiência de questionamento moral.

Gaut (2007, p. 207) afirma que essa capacidade de aprofundamento da experiência emocional é o que a arte tem para oferecer ao espectador. Ela possibilita que experiencie situações de perigo, dor ou ameaça, por exemplo, sem que precise viver a realidade dos eventos e suas consequências. Aplicada à ética, essa experiência real, mas sem consequências que afetem o mundo real, como em um jogo, é uma oportunidade de ampliação do entendimento de como se sustenta a lógica de ação por trás das escolhas de outra mente, sem que o espectador precise arcar com as consequências dessas ações.

Segundo Carrol (2003, p. 282), completar uma obra de arte é uma oportunidade de exercício dos poderes morais. O sentimento resultante do contato com a ficção fala do carácter do espectador e, por isso, tem implicações éticas. É possível imaginar algo imoral e, 
ainda assim, não sofrer o resultado disso, mas não é possível sentir uma emoção imoral ou direcionada a algo imoral e não perceber a implicação disso no caráter do espectador. Um sentimento de preconceito direcionado a um personagem é diferente de imaginar o funcionamento de uma mente preconceituosa, pois é o reflexo da percepção do próprio preconceito que resulta do ganho cognitivo.

É essa mudança de foco da moralização para a experiência que abre espaço para uma terceira corrente de avaliação ético-estética, chamada contextualismo ou imoralismo. Além de negar o autonomismo, essa corrente afirma que, em algumas situações, os problemas morais de uma obra podem ser vistos como virtudes estéticas. Gaut (2007, p. 54) defende o uso do termo contextualismo, visto que o contexto em que tal problema ocorre é o que o valida esteticamente, enquanto o uso do termo imoralismo sugeriria que sempre se deva avaliar esteticamente essas falhas morais. A corrente contextualista, fundamentalmente, permite que se avalie a arte apesar de seu caráter transgressor. Obras de arte frequentemente se posicionam como moralmente questionadoras, uma vez que essa característica vanguardista é historicamente tratada como elemento criativo comprovado pelo fato de a história da arte moderna ser, acima de tudo, uma história de conflitos e transgressões.

Para essa corrente, a validade estética de uma obra não pode, portanto, ser unicamente avaliada a partir de sua conformidade aos valores morais do período em que se insere, mas que é preciso considerar que, em algumas situações, a imoralidade da obra pode ser um mérito estético. Entretanto, o imoralismo não é proposto como uma negação à avaliação moralista, o que é, em grande parte a razão de seu insucesso em responder aos questionamentos resultantes dessa proposta. Acima de tudo, uma proposta de imoralismo que considere que possam existir situações em que falhas morais sejam méritos estéticos é tão relativista quanto a proposta eticista de que possam existir situações em que essas falhas não sejam defeitos estéticos. As proposições que procuram sustentar as duas teorias apresentam, por caminhos diferentes, o mesmo resultado e os mesmos problemas de aplicação.

Para uma definição da imoralidade na arte, Jacobson (1997, p. 156) passa também pelo que chama de tendências moralísticas disseminadas na filosofia contemporânea da arte, a saber, a defesa do moralismo e sua consideração de que todas as obras devam ter, primariamente, uma validação artística pela sua capacidade de afirmar valores morais e que, por esse ponto de vista, quaisquer falhas morais seriam, consequentemente, também falhas estéticas. 
Segundo o autor, considerando-se que, na defesa do moralismo a definição de arte imoral é a de uma obra que tenha algum defeito moral intrínseco e, reconhecendo que (1) existem visões diversas do que constitui imoralidade; (2) essas visões também divergem sobre quando falhas morais são, também, falhas estéticas; e (3) a imoralidade na arte pode ter apenas efeitos perniciosos, é preciso que se discorra sobre a importância e as implicações de uma teoria imoralista que refute tal teoria.

Primeiro, visto que moralidade varia com o tempo e lugar, e que não há consenso sobre imoralidade nem, portanto, sobre arte imoral (JACOBSON, 1997, p. 167), uma avaliação moral dependeria de um contexto de aplicação, ou seja, obras consideradas moralmente aceitáveis em um dado período poderiam ser consideradas imorais em outro ou, até mesmo, seria dependente do seu local de apresentação. Essa variação resulta desse relativismo moral que usualmente está associado à avaliação da arte, como pode ser comprovada pela moralização e ressignificação de temas como a nudez e a sexualidade em obras de arte de períodos antigos. Assim, a divergência de afirmações de imoralidade impede uma definição irrevogável do que se constitui uma obra de arte imoral. A certeza é que essa avaliação existe e que será fundamentada em valores locais, culturais e de época.

Hamilton (2006 p. 50) afirma que é papel da arte promover a investigação da ideia de que os conceitos morais não são estáticos e permanentes, mas que se alteram com o tempo e com a mudança na percepção do sujeito. A implicação dos conceitos de percepção explorados pela filosofia é clara, uma vez que a arte proporciona uma alteração na intencionalidade, no conhecimento apriorístico ou em ambos, o que propiciaria uma revisão dos conceitos morais do espectador. Para Jacobson (1997, p. 161), não apenas é possível que um defeito moral em uma obra possa contribuir positivamente para seu valor estético, mas também que é em virtude de seu potencial para a imoralidade que a arte narrativa e dramática pode servir uma importante função ética.

\section{IMORALISMO COGNITIVO}

Nessa proposta de arte como questionamento e educação a partir da imoralidade, Kieran (2006, p. 58) defende o que chama de imoralismo cognitivista, propondo que a obra pode assumir valor artístico em virtude de - e não apesar de - ter um carácter imoral. $\mathrm{O}$ cognitivismo vem da presunção de que esse valor vem da maneira como a obra aprofunda a 
compreensão e apreciação do espectador.

A imaginação pode seguir por caminhos imorais, sem que isso signifique que o espectador está assumindo ou defendendo uma ação imoral. Para Gaut (2007, p. 185), a imaginação pode auxiliar a compreensão de atitudes imorais como o assassinato, como quando um detetive imagina a sensação de sentir prazer ao matar, de modo a entender a personalidade do assassino, bem como auxiliar na compreensão da motivação de atos como o bullying, quando imaginados como uma atitude que dá prazer e poder ao seu perpetuador.

Essa capacidade de considerar o ponto de vista do outro, mesmo que essa visão seja considerada inadequada, deve ser vista como uma oportunidade de compreender a lógica que sustenta essa posição. Conforme Jacobson:

Um discurso de juízo em uma sociedade pluralista, se é para ultrapassar dogmatismos, requer que os participantes entendam como outros irão responder a suas reivindicações e razões apresentadas, [uma vez que] objetividade em assuntos éticos é menos uma visão do nada do que uma habilidade em ver as coisas imaginativamente de uma variedade de perspectivas éticas - mesmo que algumas delas sejam sistematicamente distorcidas (JACOBSON, 1997, p. 193, tradução nossa) $)^{5}$.

O ponto fundamental para o entendimento da proposta de Kieran é que a avaliação da obra de arte é a validade da experiência imaginativa por ela proporcionada. Dessa forma, obras que corroboram valores que, de outra forma, seriam estranhos ao espectador, aprofundam seu conhecimento pela oportunidade de que veja a situação por outra perspectiva. A questão passa a ser, assim, qual o benefício proveniente da experiência da imoralidade.

Kieran parte do senso comum de que a apreciação de algo bom depende do conhecimento do ruim para um detalhamento da natureza da experiência e de seu efeito cognitivo no espectador.

As etapas a seguir são proposições que detalham a argumentação do autor sobre a necessidade da experiência negativa como caso comparativo para o completo entendimento da realidade (KIERAN, 2006, p. 63):

1 - Fundamentação experiencial: ter um determinado tipo de experiência é a principal fonte de conhecimento sobre como é ter aquele tipo específico de experiência;

\footnotetext{
${ }^{5}$ Evaluative discourse in a pluralist society, if it is to rise above dogmatism, requires its participants to understant how otherswill respond to their proffered claims and reasons. [...] It is that objectivity in ethical matters is less a view from nowhere than an ability to view things imaginatively from a variety of ethical perspectives -- even though some of them will be systematically distorted.
} 
2 - restrição de apreciação: o entendimento da natureza de uma experiência depende da capacidade de assumir diferentes perspectivas e diferenciar os elementos da experiência e a participação deles na sua composição;

3 - exigência de experiência comparativa: uma completa compreensão da experiência, de seus diferentes aspectos, perspectivas e capacidades requer experiências comparativas de mesma espécie e de natureza contrastante;

4 - afirmação psicológica: os pontos 1-3 declaram que a experiência comparativa é necessária para que se apreciem completamente as diferentes informações, mas também para determinados estados cognitivo-afetivos, resultando na afirmação de que as experiências negativas sejam necessárias para a completa apreciação das positivas, embora sua obrigatoriedade como fonte cognitiva primária dependa das afirmações seguintes.

Até esse ponto, é possível perceber a relação entre a experiência e o ganho cognitivo proveniente, uma vez que (1) afirma a existência da experiência, (2) e (3) requerem a capacidade do espectador de modificar seu ponto de vista e de considerar as novas informações provenientes dessa experiência. A afirmação psicológica é o resurso de Kieran para declarar a validade dessa experiência enquanto afirma a necessidade do restante da formulação para desenvolvê-la para além do senso comum.

5 - Afirmação de prioridade: a experiência negativa de valores morais ou não morais proporciona uma espécie comparativa de experiência que não pode ser obtida de outra forma.

5.1 - Algumas experiências negativas podem, primariamente ou distintivamente, proporcionar capacidades de diferenciação ou perspectivas que são requisito para um completo entendimento e apreciação de experiências positivas.

5.2 - A afirmação anterior vale não apenas para experiências em si, mas para experiências moralmente problemáticas ou imorais.

Decorre daí uma obrigatoriedade epistemológica de que se busquem experiências negativas em tópicos em que se acredite ser necessária uma melhor ou mais profunda compreensão das experiências positivas relevantes (KIERAN, 2006, p. 67). Não resulta, entretanto, que essa obrigatoriedade diga respeito a experiências que devam provir do estado real das coisas, uma vez que a experiência imaginativa permite que se experienciem situações negativas sem a ocorrência dessas situações na realidade. Assim, a próxima etapa da formulação será destinada a validar a experiência imaginativa como uma fonte de ganho cognitivo e a possibilidade de que se jogue com as variáveis sem a preocupação com os 
efeitos advindos das ações, o que seria suficiente para garantir o prosseguimento da teoria. 6 - Afirmação da imaginação:

6.1 - A experiência imaginativa pode ser uma origem indireta de aprendizado pela experiência.

6.2 - É possível suspender o julgamento moral ou tomar posições incompatíveis com a realidade dos fatos na imaginação.

A proposta de Kieran (2006, p. 72), além de aprofundar o entendimento do efeito das experiências negativas, explica o valor associado a obras que apresentam narrativas moralmente problemáticas ou imorais, uma vez que demonstra que tais experiências têm como resultado um aprofundamento do conhecimento sobre os elementos que constituem a experiência em questão, fazendo com que existam obras em que o valor artístico é decorrente da existência da imoralidade, e não apesar dela. Entretanto, a exposição a experiências negativas não é suficiente para tal crescimento cognitivo, uma vez que o espectador pode ser exposto a situações imorais sem que isso necessariamente leve a uma reflexão sobre a moralidade, tal qual o estudo da ética não implica que o estudante se transforme em uma pessoa com comportamentos morais.

Embora se possa justificar o cognitivismo por sua oportunidade de crescimento depender de uma atitude estética apropriada do espectador, é exatamente na afirmação da imaginação (6) que a proposta de Kieran se desvia de uma defesa do imoralismo. Dado que (6.1) esteja certo e que a experiência imaginativa seja uma oportunidade de aprendizado pela experiência, (6.2) inviabiliza esse ganho cognitivo pela proposta de suspensão do julgamento moral. Essa divergência entre os pontos que constituem a proposição não coincide com uma intenção de crescimento de um conhecimento moral apriorístico, visto que a proposta de que se suspenda a avaliação moral implica uma suspensão da racionalização da experiência, o que significa afirmar que a reação à imoralidade seria apenas uma resposta automática aos estímulos sensoriais.

Tome-se como exemplo a cena central do filme Irreversível, do diretor francoargentino Gaspar Noé. Tendo o espectador compreendido o suficiente sobre a relação entre os personagens, a cena do estupro da protagonista, deslocada de seu contexto pela supressão da avaliação moral, não carrega a proposição que cria o questionamento moral de justificação do assassinato, tema central da obra. É passível de questionamento, inclusive, se essa cena do estupro, dada uma proposta de suspensão total e irrestrita do julgamento moral, derivada da 
formulação de Kieran, seria compreendida como uma cena de violência ou unicamente como uma performance sexual.

Dessa forma, ao que parece, a proposta de uma suspensão do julgamento moral, elemento constitutivo da defesa do ganho cognitivo pela experiência da arte como apresentada por Kieran, retorna à bifurcação forma-conteúdo, falha de constituição da proposta esteticista que foi suficiente para sua refutação, visto que a suspensão da moralidade não é outra coisa senão a avaliação amoral dessa corrente. Sua afirmação de um ganho cognitivo pela comparação de experiências morais positivas e negativas, entretanto, parece sólida em garantir que o conhecimento prévio do espectador seja questionado e racionalmente avaliado.

\section{CONCLUSÃO}

A formulação de Kieran, como visto, retoma os problemas do esteticismo, mas apresenta a necessidade da experiência imoral. Uma nova formulação deve considerar que o espectador experiencie o imoralismo ciente de sua imoralidade, visto que não é a experiência do ato imoral em si suficiente para gerar um questionamento moral no espectador e, inclusive, a vivência de uma imoralidade em que se desconsidere o julgamento moral leva a uma proposta oposta, em que o espectador, exatamente por estar livre dos efeitos de seus atos e desprovido de seu julgamento moral, tenha a possibilidade de se deleitar com a imoralidade, efeito que negaria a intenção do cognitivismo estético.

Pela sequência de argumentação de sua proposta do imoralismo cognitivo, poder-se-ia sugerir que Kieran procurou acrescentar a suspensão do julgamento moral com a intenção de moralizar a experiência estética, uma vez que isso liberaria o espectador de uma penitência pela vivência da imoralidade e evitaria uma apreciação dessa experiência. O argumento que parece passar despercebido pelo autor é que, na defesa de um aprender pela experiência do mau, é necessário que essa experiência seja vivida com sua máxima atenção e ciência da imoralidade. Propor uma suspensão dos conceitos morais do espectador, ao contrário, transforma essa experiência de uma oportunidade de crescimento cognitivo em uma vivência banal que, inclusive, pode vir a ter o efeito inverso do pretendido.

$\mathrm{Na}$ intenção da manutenção da proposta original de que o imoralismo cognitivo seja uma oportunidade de aprendizado moral pela experiência do imoral e que, além disso, seja uma negação do moralismo na avaliação da arte, pode-se propor que a proposição siga - mas não esteja limitada a - a seguinte formulação: 
6.2 - É necessário que a experiência imaginativa seja provida de julgamento moral quando da tomada de posições incompatíveis com a realidade dos fatos.

6.3 - A incongruência entre as atitudes imorais na imaginação e a percepção moral da realidade bem como seu efeito emocional oportunizam uma reflexão dos valores morais e um consequente ganho cognitivo.

Ficaria garantida, assim, que a experiência imaginativa da imoralidade fosse fonte de ganho cognitivo moral pelo conflito entre as posições morais do espectador e as apresentadas pelo universo ficcional da obra. O desconforto emocional provocado por esse desacordo, acredita-se, seria um motivo para a racionalização da experiência e da revisão ou defesa dos valores morais a priori.

\section{REFERÊNCIAS}

CARROL, Noël. Beyond aesthetics: philosophical essay. Cambridge: Cambridge University Press, 2003.

GAUT, Berys. Art, emotion and ethics. Oxford: Oxford University Press, 2007.

HAMILTON, Christopher. Art and moral education. In: BERMÚDEZ, José Luis; GARDNER, Sebastian. Art and morality. London: Routledge, 2006. p. 37-55.

JACOBSON, Daniel. Praise of immoral art. Philosophical Topics, Arkansas, v. 25, n. 1, p. 155-199, 1997.

KIERAN, Matthew. Forbiden knowledge: the challenge of immoralism. In: BERMÚDEZ, José Luis; GARDNER, Sebastian. Art and morality. London: Routledge, 2006. p. 56-73. 